\title{
Impact of Genetic Testing on Life Insurance
}

\section{Richard Heaney and David Pitt}

$\mathrm{T}$ he Human Genome project generates immense interest in the scientific community though there are also important issues for the business community, particularly insurance companies. The dramatic advances in our understanding of the human genetic code, or human genome, affect our understanding of the determinants of human longevity and this is critical to the profitability of life insurance contracts.

Insurance plays an important role in our economy. For example, there were 42 life insurance companies managing approximately AUD \$188 billion as at 30 June 2002 and these same companies received AUD \$38.1 billion in premium income over for the year ended 30 June 2002. Life insurance contracts are increasingly being sold in combination with superannuation where the contract forms part of the superannuation package. For example, up to 85 per cent of all life office assets and 90 per cent of the premiums were classified as superannuation business in 2001 (APRA, 2002). Regardless of whether an individual submits an application form directly to a life insurance company as part of a stand alone policy, or indirectly via superannuation, the insurance company faces the question of deciding whether they wish to sell insurance to this individual.

While life insurance policies can take a number of forms, an essential feature of these contracts is that they promise the payment of a given amount to certain beneficiaries when the insured dies. The time of death is critical to the pricing and profitability of these contracts. For insurance contracts to be profitable they must be priced so that invested premiums generate sufficient reserves to meet the payment of death benefits when they fall due.

Failure to adequately model the impact of our increased understanding of the human genome could have a dramatic impact on the profitability of insurance contracts. The mapping of the human genome and the rapid development of genetic testing means that people have access to greater knowledge about their health and longevity yet this information may not be freely available, particularly to insurers and annuity providers (Hoy and Polborn, 2000). If individuals have more information about their health than insurance companies, this can complicate the pricing of life insurance contracts and annuities. This one-sided access to information is often referred to as information asymmetry and at its worst information asymmetry can lead to market failure (Akerlof, 1970). Further, where the insurer is unable to accurately assess the risk of an applicant it is possible that prices will be set too high. The ultimate result could be that only those applicants

Richard Heaney is a Reader in Finance and David Pitt is a Lecturer in Actuarial Studies in the School of Finance and Applied Statistics at the Australian National University. 
most likely to require a payout will purchase the product resulting in low profitability or losses. This is a critical problem in the pricing of life insurance products. Life insurers generally attempt to protect themselves through pricing for average risks though this may become more difficult where information about health and longevity is restricted in an asymmetric manner. An objective of this paper is to show that failure to adequately model the impact of our increased understanding of the human genome - on choices made by consumers, and on the pricing policies of insurance companies - could have a dramatic impact on the profitability of insurance contracts.

While Doherty and Thistle (1996) and Hoy and Polborn (2000) provide economic analysis of the impact of information about the human genome, the work of actuaries such as Macdonald (1997) provides insight into the problems that actuaries face in the day-to-day pricing of life insurance contracts. We apply the MacDonald (1997) model to gain further understanding of the impact of genetic research on Australian life insurance contracts - in particular, the effects on profitability of adverse selection by consumers who discover themselves to be high risk, and who subsequently purchase more insurance than would otherwise have been the case. The following section provides a brief review of the literature. It is followed by two sections that respectively describe the model used in the simulation of the insurance problem faced by Australian insurance companies, and the results of the simulation. Conclusions are drawn in the final section of the article.

\section{Insurance Theory}

Transactions costs are an important part of the market for life insurance (Gravelle and Rees, 1985). One of these costs is the cost of identifying the true risk of the individual. Individuals could be classified into broad categories such as good risk, where there is little risk of a claim, and bad risk, where the probability of a claim is high. Insurers generally assess the probability of death through analysis of objective factors, such as age and occupation, and subjective factors, such as exercise, diet and habits such as smoking. Each applicant is assessed for these factors and a premium estimated and charged.

Where it is impossible to identify the risk associated with a group of individuals, adverse selection can lead to bad risks driving out good risks. This effect could arise where the insurer initially sets the insurance premium too high for the best risks. Given the high price the best risk group choose not to insure, leaving only those representing poorer risks for the insurer. The difficulty for the insurer is that the premium does not allow for exclusion of the best risk group with the loss of the best risk group the current premium is set too low to cover the expected costs of the contract. Over time as the level of claims follows the actual longevity of the insured group, the insurer is forced to raise the level of premiums. Again, the better risks in the group choose not to insure at this higher price and so the cycle continues until the good risks are priced out of the market and the insurer faces ruin. 
In effect, the insurer faces a trade off between the costs of obtaining better information about individuals and thus pricing insurance contracts properly and the reduced profitability arising from the impact of bad risks driving out good risks when insurance premiums do not properly reflect the risk of the insured group. A regulatory response to this type of problem occurring in the health insurance area has been the use of community rating in the pricing of health insurance.

There may be signalling effects arising from the decision of insurance companies to sort into risk categories. A rational response from low risk applicants is to signal quality in order to support a separating equilibrium and receive lower premiums; from high risk applicants the response is to mix signals in order to keep a pooling equilibrium, whereby the cost of their insurance is spread across a larger group (and thus lower premiums).

The impact of genetic information on the life insurance market is important though current research suggests that the net welfare effect of genetic testing is not clear. For example, Hoy and Polborn (2000), extending the model of Doherty and Thistle (1996), show that the private value of being informed is positive for the individual while the social value of the information could be either positive or negative. Their model includes the impact of genetic testing and it is assumed that there is an incentive for an individual to undertake the test to obtain further information about their health with the knowledge that the insurer does not have access to this information. Essentially there are three groups in the model, high risk, low risk and the uninformed.

Hoy and Polborn focus on the benefits to those in the uninformed group who choose to test, assuming that the current price of insurance is only attractive to high-risk individuals. If the uninformed choose the test and are found to be bad risks, then they can insure, and so they are better off. If they are good risks, then they can choose not to insure. In this partial equilibrium model the uninformed are better off with the availability of the test because they have the option to purchase a contract at the old price if they test positive. There are also spillover effects associated with those who choose not to take the test where the actual risk of this group differs from the average risk for the pool. For example, the spillover effect is positive if the initially uninformed (who are tested and subsequently buy insurance) are lower risk than the existing customers. Hoy and Polborn argue that this source of asymmetric information is not unusual as there is legislation in a number of countries specifically set up to protect the rights of the individual to genetic testing results and to deny the insurance companies control over this information. This debate continues in Australia and is surveyed in Otlowski (2002).

Thus the impact of the introduction of genetic testing is not clear. Hoy and Polborn (2000) argue that, when information is distributed symmetrically between insurers and customers, the introduction of the test is welfare reducing for consumers, assuming that markets stay open (although price may vary) that the benefits arising from the use of genetic testing, including improved medical treatment of these conditions, are ignored. With asymmetric information the net 
welfare effects of the test could be positive, negative or a mixed case where those who undertake the test gain and those that choose not to undertake the test lose.

This theoretical work on insurance and asymmetric information helps to understand the implications of genetic testing and highlights the impact of asymmetric information but it tells us little about the actual pricing of life insurance where genetic testing is available to individuals but not to insurers. In the following section we focus on empirical testing. Actuaries have an important role to play in valuing these instruments through statistical modelling and we use the Markov model developed by Macdonald (1997) in analysis of the impact of genetic testing on breakeven insurance premiums. As indicated above, knowledge of the mortality of a group of individuals is critical to the accurate pricing of insurance offered to the members of this group and, given information asymmetry, genetic testing could have a dramatic effect on the pricing of life insurance.

\section{Actuarial Modelling}

Actuarial research into the financial impact of genetic testing has gained momentum in recent years. MacDonald (1997 and1999) has published a number of papers advocating the use of multi-state Markov models to explore the impact of uncertainty on traditional life insurance products where an individual has access to information such as genetic testing results but the insurer does not have access to this information. This is particularly important to insurers where the tests provide highly predictive information about mortality.

A thorough assessment of the impact of genetic testing involves consideration of four major factors. The first factor reflects the level of insurance that the applicant might prefer. The level of insurance could vary with the existence of a genetic predisposition to a particular disease. It could also vary with whether the applicant has been genetically tested. A final source of variation lies with whether the applicant has been genetically tested and found not to have a higher probability than normal of contracting a particular disease (negative results). The second factor is the prevalence and predictive accuracy of genetic tests. The third factor is the proportion of those who have genetic tests and who return a positive result indicating that they have a higher probability than normal of contracting a particular disease. The final factor is the extent to which people who receive a positive genetic test for a particular disease have an increased propensity to purchase insurance.

The most significant financial impact of genetic testing is thought to occur for life insurance products such as term insurance and associated riders such as dread disease insurance. Dread disease insurance is a rider that may be added to a contract containing death insurance. This rider provides the insured with a benefit if they incur one of a selection of serious medical conditions listed in the policy.

Genetic testing is more important for term insurance than whole of life insurance because in the case of whole of life insurance the insured is guaranteed payment of the amount insured on death. The only question for whole of life insurers is the timing of the payment. Under a term insurance contract the amount 
insured is paid if the insured dies before the term of the contract and so the insurer prices the contract with a view to both the timing of death and the likelihood of death before expiry of the contract. Thus where the insured has a genetic predisposition for higher mortality they are more likely to purchase a term insurance contract because the premium is lower for term insurance contracts than for whole of life contracts. This is because lower risk is ordinarily presented to the insurer for term insurance contracts.

Commonly term insurance is provided for a period of 10 or 20 years. These types of insurance contracts are often called risk-based products. In the Australian setting the majority of the term insurance business is renewed each year, or yearly renewable. These insurance products give the insured the option to renew the insurance contract each year and the insurer is obligated to renew the coverage at the request of the insured as long as there is no material change to the risk presented by the insured. This arrangement provides considerable potential for adverse selection against the insurer and so it is important to model the impact on life insurance contract premiums.

\section{A benchmark Markov model with no genetic test}

First, let us consider the case of a customer who purchases life insurance when genetic testing is ignored. This model will be used as the benchmark case for analysing the effects of adverse selection on the profitability of term insurance contracts. Consider a typical individual who purchases insurance cover at age 30 for the first time. This life insurance coverage provides payment of the sum insured, typically $\$ 100,000$, on the death of the insured individual and the payment is made to the estate of the insured individual. We will assume that this individual has purchased cover for 20 years payable by annual premiums. The insured renews the policy annually by paying a level annual premium for twenty years or until earlier death.

The situation can be illustrated as in Figure 1, which shows transitions between three 'states'. State 1 is where all people who have not purchased life insurance are situated. If an individual purchases life insurance, they move from State 1 into State 2. This move between states is called a transition and in Figure 1 this transition is labelled transition $\mathrm{t} 1$. In this model people who have purchased life insurance, and therefore reside in State 2, can of course die. Death causes them to move to State 3 and, as shown in Figure 1, make transition t3. Individuals who have not purchased life insurance, and therefore reside in State 1, can also die and move to State 3 . This movement from the uninsured state (State 1) to the dead state (State 3) is labelled transition $\mathrm{t} 2$. If the consumer makes an annual decision whether to renew the contract, the transition probabilities reflect the likelihood of the event (transition) occurring within a particular year for a person of certain age.

In this three-state model, where we ignore the impact of genetic testing, the annual premium paid by an insured individual depends only on two key factors. The first and most significant is the magnitude of transition intensity t 3 - the 
mortality of insured individuals. In practice these mortality rates (which vary with age) are determined by considering the experience of the particular insurer and also by consulting published Australian mortality tables. The other important factor is the investment income that the insurer is assumed to be able to earn on the premiums paid by the insured to the insurer. The insurer can earn substantial amounts of investment income from the prudent investment of premium income. This is because under term insurance the premiums are paid to the insurer long before any insurance payment is made, if it is ever made, to the estate of the insured individual. The assumed rate of investment income is again determined by reference to the recent investment returns earned by the insurer on the funds that are backing the relevant insurance portfolio. In this analysis we have ignored the impact on premiums charged to consumers of commissions and other expenses that the insurer would ordinarily incur.

Figure 1: Markov Model for Term Insurance in the Absence of Genetic Testing

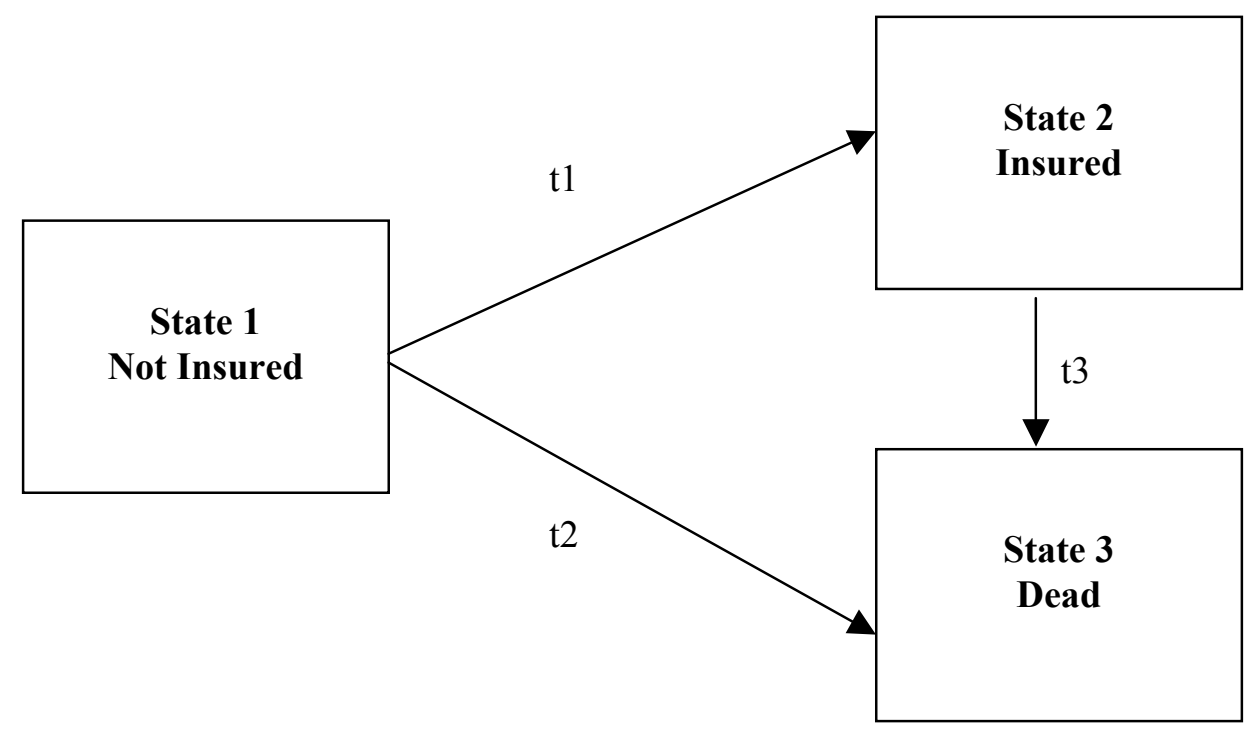

\section{A Markov model with genetic testing}

We now consider the case where the impact of genetic testing is taken into consideration in the determination of suitable insurance premiums. MacDonald (1997) models individuals as occupying a series of states and making transitions from state to state until they die. The important linkages modelled by MacDonald are identified in Figure 2. 
Figure 2: Markov Model for Assessing the Impact of Genetic Testing on Insurer Profitability.

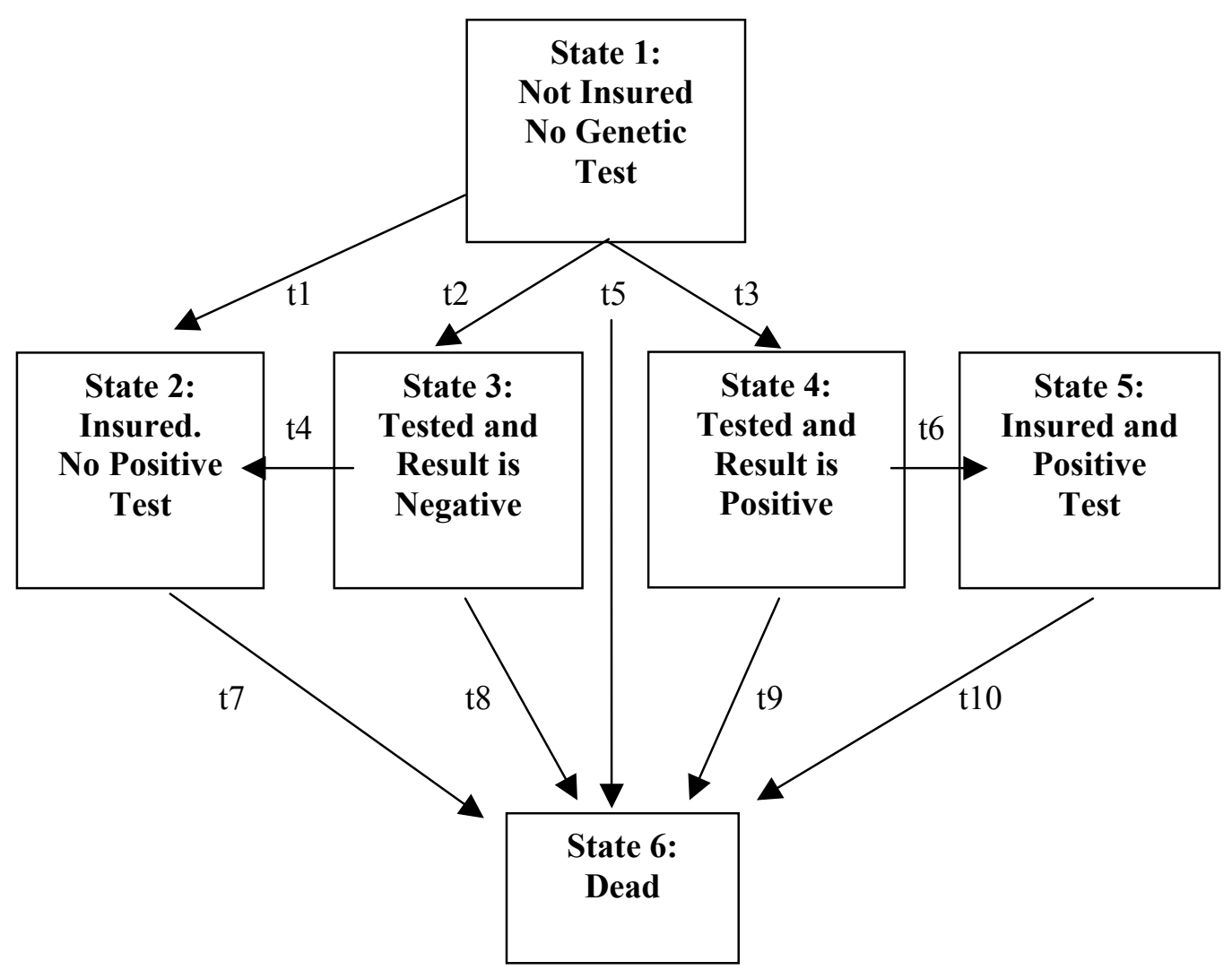

As in the previous diagram, each box in Figure 2 represents a state in which either a consumer or potential consumer of life insurance could be situated. In any interval of time the consumer is able to make a transition along any of the arrows. Each transition has a simple description. Transition $\mathrm{t} 1$ occurs when an individual who has not had any genetic testing purchases insurance. Transitions $t 2$ and $t 3$ occur after a genetic test is performed on the consumer. The consumer makes transition $\mathrm{t} 2$ if the test result is negative indicating that they do not suffer from the conditions identified in genetic testing. The consumer makes transition $\mathrm{t} 3$ if the test result is positive and the genetic tests identify the consumer as suffering from the tested ailments. Transitions $t 4$ and $t 6$ occur when an individual purchases life insurance after testing. While the transition $\mathrm{t} 4$ is reserved for those individuals who purchase insurance after returning a negative genetic test, transition t6 is made when purchasing insurance for those individuals who returned a positive 
genetic test. The remaining transitions ( $\mathrm{t} 5, \mathrm{t} 7, \mathrm{t} 8, \mathrm{t} 9$ and $\mathrm{t} 10)$ occur on the death of an individual from any of the five other states in the model.

It is clear that the model in Figure 2 is an extension of the model in Figure 1. States 1, 2 and 3 in the model that ignores genetic testing (Figure 1) correspond to states 1,2 and 6 respectively in the model where genetic testing is considered (Figure 2).

An important feature of this model is that the likelihood of some of the transitions (those other than death, which obviously vary with age) depend only on the state currently occupied by the insured. The model ignores information about past movements between particular states of the model. For example, the probability that an individual who returned a positive genetic test two years ago will buy insurance in the next week is the same as the probability that an individual who has just returned a positive genetic test will purchase insurance in the next week. In Figure 2, this is the same as saying that the chance of moving from State 4 to State 5 is unrelated to the amount of time spent in State 4.

In addition to considering the probabilities of transitions between states, consideration must also be given to the payments made where applicable while residing in states and on the transition between states. In Figure 2, the premiums are paid to the insurer while the insured is in states 2 and 5. This is because when an individual is in state 2 or state 5 the individual has life insurance. On transition from state 2 or state 5 to state 6 (that is on the death of an insured whether or not that individual had returned a positive genetic test) a payment is made to the estate of the insured person. This payment is the amount of life insurance purchased by the insured.

The model aims to determine the impact on insurer profitability of varying the modelled probabilities of transition between particular states. It is of particular interest to understand the impact of adverse selection, reflected by the increased likelihood that individual will purchase insurance if the individual knows that they have a genetic predisposition to higher mortality than average. This is modelled by increasing the probability of making the transition t6 to a multiple, greater than one, of the chance of making transition t5. Another issue of concern to insurers is the level of insurance sought by those who have returned a positive genetic test result compared with those who have returned a negative test result or who have not had a genetic test at all. This can be explored in this model by allowing the insurance amount that the insured chooses to vary. The relevant insurance amount is the amount paid on transition from state 5 to the dead state, and it can be modelled to be double or four times the amount paid on transition from state 2 to the dead state.

\section{Pricing of Life Insurance Contracts}

To gain some idea of the impact of changes in the level of information asymmetry on the profitability of insurance policies we vary the size of the amount insured and the probability of purchasing insurance for those who have returned a positive genetic test and therefore exhibit higher mortality. We then focus on the break- 
even premium for the group of individuals insured. This is the premium charged to all those insured within a particular group regardless of whether a genetic test has been conducted and irrespective of the results of the test where it is undertaken. The model has been run using Australian mortality data based on the IA95-97 Life Table. This life table is produced by the Institute of Actuaries of Australia Mortality Committee and is based on the mortality experience of the major life insurers operating in Australia during the years 1995 to 1997 . The interest rate is assumed to be 5 per cent per annum compounding continuously in the model and expenses have been ignored in this analysis.

The projected increase in mortality resulting from a positive genetic test clearly needs to be estimated for inclusion in the model. This increase is represented by the difference between the probabilities of making the transitions $t 9$ and $\mathrm{t} 10$ and the other transitions to the dead state, namely t5, t7 and t8. For the purposes of this analysis a 50 per cent increase in mortality has been assumed for those who are insured and who have returned a positive genetic test. An extreme value of 0.90 and a less extreme value of 0.30 have been used for the conditional probability that an individual, given that they have returned a positive genetic test, will buy insurance.

A summary table of the transition intensities is shown below in Table 1.

Table 1: Transition Intensities used in the Term Insurance Analysis in the presence of Genetic Testing

\begin{tabular}{|l|c|}
\hline \multicolumn{1}{|c|}{ Transition Description } & Transition Intensity \\
\hline Transition $\mathrm{t} 1$ & 0.50 \\
\hline Transition $\mathrm{t} 2$ & 0.20 \\
\hline Transition $\mathrm{t} 3$ & 0.05 \\
\hline Transition $\mathrm{t} 4$ & 0.05 \\
\hline Transition $\mathrm{t} 6$ & 0.30 and 0.90 \\
\hline Transitions $\mathrm{t} 5, \mathrm{t} 7, \mathrm{t} 8$ at age 30 & 0.00113 \\
\hline Transitions $\mathrm{t} 5, \mathrm{t} 7, \mathrm{t} 8$ at age 45 & 0.00139 \\
\hline Transitions $\mathrm{t} 5, \mathrm{t} 7, \mathrm{t} 8$ at age 60 & 0.00568 \\
\hline Transitions $\mathrm{t} 9$ and $\mathrm{t} 10$ at age 30 & 0.00170 \\
\hline Transitions $\mathrm{t} 9$ and $\mathrm{t} 10$ at age 45 & 0.00209 \\
\hline Transitions $\mathrm{t} 9$ and $\mathrm{t} 10$ at age 60 & 0.00852 \\
\hline
\end{tabular}


Once transition probabilities are assigned it is necessary to select the amount that individuals would choose to be insured for. With these inputs identified, the statistical model generates the level of premium required for the insurer to break even. This model provides considerable flexibility in helping insurers to make informed decisions about the level of premiums that should be charged. The model enables the insurer to vary transition probabilities as well as the sum insured and then consider the impact of these choices on the insurer's break even level of premiums.

The critical factor for an insurer is the impact of genetic testing on the profitability of insurance contracts where the insured is aware of the impact of genetic test results though the insurer is not. In Table 2 we report the results of varying the age, term of the insurance policy and the amount insured given that the individual has returned a positive genetic test. The table provides the increased premium rates required for conventional term insurance policies sold to people aged 30 or 40 and who hold life insurance contracts for terms of either 10 or 20 years. For comparison the table reports the increases in required premiums for values of t6 equal to both 0.90 and, in brackets, for t6 equal to 0.30 . This shows how sensitive the required premium increases are to the extent of the modelled adverse selection. From Table 2 it is clear that the most significant premium increases occur when those insured, who have returned a positive genetic test, request higher amounts of life insurance coverage. This increase in premiums is required because large insurance payments will be paid more often as the probability of death for individuals who returned a positive genetic test is higher than for other individuals on average.

Table 2: Premium Rate Increases Required in The Presence of Adverse Selection

\begin{tabular}{|l|c|c|c|c|}
\hline $\begin{array}{c}\text { Sum Insured of } \\
\text { Positive Test }\end{array}$ & $\begin{array}{c}\text { Age 30 } \\
\text { Term 10 yrs }\end{array}$ & $\begin{array}{c}\text { Age 30 } \\
\text { Term 20 yrs }\end{array}$ & $\begin{array}{c}\text { Age 40 } \\
\text { Term 10 yrs }\end{array}$ & $\begin{array}{c}\text { Age 40 } \\
\text { Term 20 yrs }\end{array}$ \\
\hline Normal & $4.5 \%$ & $2.7 \%$ & $4.5 \%$ & $2.7 \%$ \\
& $(3.0 \%)$ & $(2.0 \%)$ & $(2.9 \%)$ & $(1.6 \%)$ \\
\hline $2 *$ Normal & $11.0 \%$ & $7.2 \%$ & $11.1 \%$ & $7.3 \%$ \\
& $(6.8 \%)$ & $(5.7 \%)$ & $(6.9 \%)$ & $(5.4 \%)$ \\
\hline $4 *$ Normal & $22.3 \%$ & $17.6 \%$ & $22.5 \%$ & $17.2 \%$ \\
& $(14.0 \%)$ & $(13.1 \%)$ & $(14.3 \%)$ & $(13.6 \%)$ \\
\hline
\end{tabular}

Note: Values in brackets show the required increase in premium rates when t6, the transition intensity for those who have returned a positive genetic test, is 0.30 . The values not in brackets show the required increase in premium rates when t6 is 0.90 . 
As those with a positive genetic test who choose to buy insurance increase the amount insured, the break-even premium increases markedly regardless of the age of the insured or the term of the insurance contract. For example, if those insured with a positive genetic test choose a normal level of insurance then the adjustment to the overall break even premium for the insurer with the introduction of genetic testing is fairly small, either 2.7 per cent or 4.5 per cent in Table 2. In contrast where the amount insured is quadrupled by those insured who have received a positive genetic test, the overall break even premium increases by as much as 22.5 per cent. Further, increases in the term of the life insurance contract tend to reduce the impact on the break-even premium. For example, given that the insured is aged 30, we note that the required percentage increase in break-even premium reduces from 22.3 per cent to 17.6 per cent with an increase in term from 10 years to 20 years. Thus the impact of genetic testing on the pricing of life insurance can be substantial where the insurer does not have access to the results of the genetic tests.

\section{Conclusions on Pricing of Life Insurance Contracts}

These examples show that genetic testing is capable of changing the way the financial services industry operates. In particular, risk-based insurance products are highly vulnerable to information asymmetry. The implication from the theoretical literature is that without a solution to the information problem, we can get a rational response from insurance companies to raise premiums that may accentuate adverse selection effects as more of the low risk applicants withdraw from the insurance market.

This paper has brought together some of the work by both economists and actuaries in an Australian context and includes a simple modelling exercise designed to highlight the impact of information asymmetry on break-even life insurance premiums. The main message from the paper is that while genetic testing presents a further form of information asymmetry for the insurer, it only generates significant financial implications when

- those individuals who have returned a positive genetic test not only have an increased likelihood of purchasing insurance but also

- request significantly higher amounts of insurance coverage.

A clear policy recommendation arising from this work is that insurers be allowed the right to require access to genetic testing information under certain circumstances - a particular circumstance addressed in this paper is where the applicant requests a sum insured well in excess of the level ordinarily sought by potential purchasers of life insurance. In this case it is critical to the profitability and solvency of insurance companies that they have access to genetic test results. One fear might be that potential customers, who are unable to get high amounts of life insurance coverage with one insurer, might purchase standard amounts of life 
insurance coverage from a large number of different insurers and hence create serious problems for the life insurance industry. Contracts of life insurance require applicants for life insurance to disclose whether they already have life insurance with any other insurers and also whether they have been rejected for life insurance cover in the past. This means that, apart from cases of fraud, the insurance industry can stop people entering into multiple life insurance contracts.

The key message of this paper indicates that failure to address this information asymmetry could prove costly to the life insurance industry and could also threaten the viability of a comprehensive, well functioning insurance market.

\section{References}

APRA (2002), 'Life Insurers Statistics', http://www.apra.gov.au/Statistics/Life-InsuranceMarket-Statistics.cfm

Akerlof, G. (1970), 'The Market For 'Lemons': Qualitative Uncertainty And The Market Mechanism,' Quarterly Journal of Economics 84:488-500.

Doherty, N. and P. Thistle (1996), 'Adverse Selection with Endogenous Information in Insurance Markets', Journal of Public Economics 63: 83-102.

Gravelle, H. and R. Rees (1985), Microeconomics, Longman, London and New York.

Hoy, M. and M. Polborn (2000), 'The Value of Genetic Information in the Life Insurance Market', Journal of Public Economics 78: 235-252.

Macdonald, A. (1997), 'Current Actuarial Modelling Practice and Related Issues and Questions', North American Actuarial Journal 1:24-35.

Macdonald, A. (1999), 'Modelling the Impact of Genetics on Insurance', North American Actuarial Journal 3:83-105.

Otlowski, M. (2002), 'Genetic Testing and Insurance: The Case for Regulation', Agenda 9:335-354.

This article was stimulated by a recent conference on Genetics and Financial Services organised by the Centre for Actuarial Research at the ANU's School of Finance and Applied Statistics, the Institute of Actuaries and the Securities Institute. The authors would like to extend thanks to the reviewers for their helpful comments. 